\title{
Cognition and health-related quality of life in chronic well-controlled patients with partial epilepsy on carbamazepine monotherapy
}

Citation for published version (APA):

Engelberts, N. H. J., Klein, M., van der Ploeg, H. M., Heimans, J. J., Jolles, J., \& Trenite, D. K-N. (2002). Cognition and health-related quality of life in chronic well-controlled patients with partial epilepsy on carbamazepine monotherapy. Epilepsy \& Behavior, 3(4), 316-321. https://doi.org/10.1016/S15255050(02)00036-7

Document status and date:

Published: 01/01/2002

DOI:

10.1016/S1525-5050(02)00036-7

Document Version:

Publisher's PDF, also known as Version of record

Please check the document version of this publication:

- A submitted manuscript is the version of the article upon submission and before peer-review. There can be important differences between the submitted version and the official published version of record.

People interested in the research are advised to contact the author for the final version of the publication, or visit the DOI to the publisher's website.

- The final author version and the galley proof are versions of the publication after peer review.

- The final published version features the final layout of the paper including the volume, issue and page numbers.

Link to publication

\footnotetext{
General rights rights.

- You may freely distribute the URL identifying the publication in the public portal. please follow below link for the End User Agreement:

www.umlib.nl/taverne-license

Take down policy

If you believe that this document breaches copyright please contact us at:

repository@maastrichtuniversity.nl

providing details and we will investigate your claim.
}

Copyright and moral rights for the publications made accessible in the public portal are retained by the authors and/or other copyright owners and it is a condition of accessing publications that users recognise and abide by the legal requirements associated with these

- Users may download and print one copy of any publication from the public portal for the purpose of private study or research.

- You may not further distribute the material or use it for any profit-making activity or commercial gain

If the publication is distributed under the terms of Article 25fa of the Dutch Copyright Act, indicated by the "Taverne" license above, 


\title{
Cognition and health-related quality of life in chronic well-controlled patients with partial epilepsy on carbamazepine monotherapy
}

\author{
Nadine H.J. Engelberts, ${ }^{\text {a,* }}$ Martin Klein, ${ }^{b}$ Henk M. van der Ploeg, ${ }^{b}$ Jan J. Heimans, ${ }^{c}$ \\ Jelle Jolles, ${ }^{\mathrm{d}}$ and Dorotheé G.A. Kasteleijn-Nolst Trenité \\ ${ }^{a}$ Dutch Epilepsy Clinics Foundation, Meer \& Bosch, Achterweg 5, Heemstede SW 2103, The Netherlands \\ ${ }^{\mathrm{b}}$ Department of Medical Psychology, Vrije Universiteit Medical Center, Amsterdam BT 1081, The Netherlands \\ ${ }^{\mathrm{c}}$ Department of Neurology, Vrije Universiteit Medical Center, Amsterdam MB 1007, The Netherlands \\ d Department of Psychiatry and Neuropsychology, Maastricht University, Maastricht MD 6200, The Netherlands \\ e Department of Neurology, Medical Center Alkmaar, Alkmaar JD 1815, The Netherlands
}

Received 18 April 2002; received in revised form 11 July 2002; accepted 12 July 2002

\begin{abstract}
As a group, patients with epilepsy have reduced neuropsychological functioning and health-related quality of life (HRQOL), but the status of these factors is uncertain in seizure-free patients with seizure onset in adulthood on monotherapy. Nevertheless, some of these patients report neuropsychological problems. We hypothesized that subtle impairments in neuropsychological functioning and HRQOL may be underdiagnosed and related to these problems. Sixteen patients with localization-related epilepsy on monotherapy carbamazepine were compared with 16 age-, gender-, and education-matched healthy controls by means of a standardized neuropsychological screening battery, questionnaires about HRQOL (Short-Form Health Survey, SF-36), self-perceived neuropsychological functioning (Cognitive Failure Questionnaire), and mood (Profile of Mood States). No objective impairments in selective attention, memory, and executive functioning were found. However, a lower speed of information processing affecting everyday life functioning was found. Lower levels of self-perceived neuropsychological functioning were reported, whereas HRQOL was unimpaired relative to healthy controls. Physicians should not be reassured when patients receive adequate medication that prevents seizures; careful follow-up of speed of information processing and self-perceived neuropsychological functioning is needed. (C) 2002 Elsevier Science (USA). All rights reserved.
\end{abstract}

Keywords: Partial epilepsy; Self-perceived neuropsychological functioning; Memory; Attention; Health-related quality of life

\section{Introduction}

Most studies into cognition and health-related quality of life of patients with epilepsy do not distinguish between subgroups of epilepsy patients [1], although these patients cannot be considered a homogeneous group [2]. High seizure frequency and seizure onset in childhood are more likely to be associated with, for instance, negative effects on the patient's everyday life functioning $[3,4]$. Other epilepsy-related factors such as early age at seizure onset, duration of epilepsy, generalized seizures,

${ }^{*}$ Corresponding author. Fax: +31-23-5294055.

E-mail address: nengelberts@hotmail.com (N.H.J. Engelberts). and polytherapy with antiepileptic drugs (AEDs) also affect neuropsychological functioning [5-7] and healthrelated quality of life (HRQOL) [8-12]. When researchers investigate patients with epilepsy who responded positively to medication, they tend to include complex or mixed patient groups, ranging from patients with seizures and several AEDs to patients without ongoing seizures on monotherapy. These differences in epilepsyrelated factors make firm conclusions about cognition and HRQOL in epilepsy patients in general impossible and thus distinct epilepsy groups should be studied separately to disentangle the effects of epilepsy itself, medication, and other factors. 
Due to improvements in medical and neurosurgical treatment the subgroup of well-controlled epilepsy patients is growing. These patients no longer experience seizures and are classified as well-controlled patients because they are expected not to be limited in their daily life by their epilepsy.

In their large study on 200 epilepsy patients who attended regular jobs, Loiseau et al. [13] in 1983 showed that objective neuropsychological functioning was impaired in comparison to healthy controls. Only, $31 \%$ of the patients were seizure-free and $72 \%$ had epilepsy longer than 7 years. The patients included were both well-controlled epilepsy patients and a small number of recently diagnosed patients. In a recent study of outpatients from a specialized epilepsy center, "relatively well-controlled" epilepsy patients were investigated who were treated with monotherapy, had one seizure per month or less, and attended regular jobs [14]. Fifty percent of the 56 patients were seizurefree for more than 2 years and suffered from epilepsy for more than 7 years. We showed impaired objective neuropsychological functioning and lower levels of selfperceived neuropsychological functioning, and there was evidence of suppressed HRQOL compared with matched healthy controls in this study [14]. Of the studies on cognition mentioned above, none investigated well-controlled epilepsy patients exclusively. Therefore, no conclusions about the supposedly unimpaired objective neuropsychological functioning in these patients can be drawn.

In a study on HRQOL in well-controlled epilepsy patients, high levels of adjustment to their chronic illness and low levels of distress were reported [11]. HRQOL appears to be unaffected, but well-controlled epilepsy patients have never been compared with matched healthy controls.

The aim of this study was to investigate whether well-controlled epilepsy patients with late age at onset and long duration of epilepsy who have been seizurefree for more than 2 years have impaired objective neuropsychological functioning and suppressed HRQOL and report impaired self-perceived neuropsychological functioning compared with matched healthy controls. If the self-perceived neuropsychological functioning was suppressed among this group, the next step was to investigate if it could be associated with impaired objective neuropsychological functioning, suppressed HRQOL, or suppressed mood of the patients. The patient and control groups were compared on measures related to attentional processes, memory functioning, and speed of information processing. These measures were selected because of earlier research that had shown sensitivity in the detection of subtle neurocognitive impairments in patient groups (e.g., cognitive aging) [15].

\section{Methods}

\subsection{Patients and procedures}

One hundred eighty-four eligible outpatients with partial epilepsy were identified from January to March 1998 from three outpatient clinics of the Dutch Epilepsy Clinics Foundation in The Netherlands (Heemstede, Amsterdam, and Utrecht). First, medical chart audits were performed to check inclusion criteria: (1) partial epilepsy; (2) carbamazepine (CBZ) monotherapy; (3) $18 \geqslant$ age $\leqslant 65$. Exclusion criteria were: (1) present use of psychoactive drugs or antiepileptic drugs other than CBZ; (2) additional neurological or psychiatric disease; (3) severe perceptual deficits; (4) a history of head injury, status epilepticus, neurosurgery, or neuropsychological evaluation within the last year. The eligibility criteria based on information of the medical charts were met by 148 outpatients. In the second step, 70 patients from whom informed consent was received were tested. The selection procedure is described in detail elsewhere [14].

To select well-controlled epilepsy patients, the following criteria had to be met; (i) seizure-free for at least 2 years; (ii) epilepsy duration of at least 7 years; (iii) epilepsy onset after completion of high school. These three criteria excluded possible effects of confounding factors. Eventually, 16 patients remained.

Educational attainment was rated on an ordinal scale ranging from 1 (incomplete primary) to 8 (university); 2 points on this scale indicate a completed primary education, and 5, 6, and 7 points indicate completed lower, middle, and higher secondary education, respectively.

A control group of healthy persons was selected comparable in age, gender, and education to the patient group from a large, cross-sectional study of the biological and psychological determinants of cognitive aging involving 1940 subjects aged 25-80 years: the Maastricht Aging Study [16]. These persons had been carefully screened for medical and psychosocial risks potentially affecting cognitive functioning, and can be regarded as an optimal normative control group of healthy controls. For the questionnaire about HRQOL, the SF-36 Health Survey, an individually matched sample on age, sex, and education was drawn from other normative data [17]. This questionnaire was validated among healthy Dutchspeaking residents [18]. No data for the Dutch short version of the Profile of Mood States (POMS) were available for these groups of matched healthy persons.

\subsection{Neuropsychological functioning}

An Intelligence Quotient estimate was made by means of the Dutch version of the Primary Mental Abilities test called the Groninger Intelligence Test (GIT) [19]. Three different cognitive domains were studied. 
Selective Attention was indexed by the Stroop ColorWord Test (SCWT) [20]. In this test, subjects have to read words on card I, and subsequently name colors on card II. Card III involved color names again, but the printing ink was different from the color name. The subjects were asked to name the color of the printing ink and not read the word that interfered, all as fast as they could. Lower scores indicate better performance. Interference is expressed by the score on card II subtracted from the score on card III.

Verbal memory was assessed with the Auditory Verbal Learning Test (AVLT) [21]. Here a subject is asked to learn 15 nonrelated words over five auditory trials. Primary recall after the first presentation is considered a measure of working memory. Memory encoding and retrieval are tested in the delayed recall after $20 \mathrm{~min}$. More remembered words indicate better memory function.

Retrieval from semantic memory was indexed by the Categoric Word Fluency Task (Fluency) [22], which consists of one subtask, in which subjects are asked to name as many animals as they could within $1 \mathrm{~min}$ (Fluency). The performance on this task is taken as a measure of retrieval from semantic memory. This variable is usually considered to reflect an important aspect of executive functioning. Higher scores indicate better executive functioning.

\subsection{Self-perceived health-related quality of life}

Self-perceived health-related quality of life was assessed by means of the Short-Form Health Survey (SF36) [18]. The SF-36 is a self-report questionnaire that covers the following eight dimensions of health: physical functioning, role limitations due to physical health problems, bodily pain, general health perceptions, vitality, social functioning, role limitations due to emotional problems, and general mental health. Two higher-order compound scores are computed: mental compound score (MCS) and physical compound score (PCS). Higher scores indicate better HRQOL.

\subsection{Self-perceived neuropsychological functioning}

Self-perceived neuropsychological functioning was assessed using the Cognitive Failure Questionnaire (CFQ) [23], a 25-item self-report questionnaire that requires subjects to provide ratings of the perception of frequency of various cognitive slips in daily life, higher scores indicating more cognitive slips (CFQ).

\subsection{Self-perceived mood}

Self-perceived mood was investigated with the Dutch short version of the POMS to measure the extent to which mood influences test scores [24]. The question- naire consists of 32 words that describe mood states. Adult and geriatric normative data and validation of the profile of mood states are available for the Dutch population [25].

\subsection{Data analysis}

Univariate analysis of variance (ANOVA) was used to determine if objective, self-perceived neuropsychological performance and self-perceived HRQOL of the well-controlled patients differed from those of the healthy controls (see Table 2). To correct for multiple testing we restricted $\alpha$ to $1 \%$.

To investigate the association between overall selfperceived neuropsychological functioning investigated with the CFQ total score, objective neuropsychological functioning as indexed by Total Recall score (VVLT), card I (SCWT), Interference score (SCWT), and overall self-perceived HRQOL measured with MCS and PCS, Pearson's correlations were calculated. In addition, associations between the five subscales of the POMS (tension, depression, anger, vigor, and fatigue) and the four dimensions of the CFQ (absentmindedness, problems with social interactions, difficulties remembering names and words, difficulties with orientation) were investigated.

\section{Results}

Table 1 lists the patients' clinical and biographical characteristics. The mean age of the patients was 45.9 years. Eleven of the sixteen patients were male. The mean duration of epilepsy was 16 years, ranging from 7 to 41 years. The mean age at onset was 30 years, ranging from 18 to 48 years. The epileptogenic zone was localized to the frontal lobe in four patients, the temporal lobe in five patients, the frontotemporal in six patients, and the occipital lobe in one patient.

The healthy controls were matched successfully since they had a mean age of 45.5 years, and 11 patients were male. The level of education ranging from level 1 to level 8 was 5.3 compared with 5.6 in the patient group. Thus, all patients completed lower secondary education. The IQ estimate for the patients (115.8) did not differ significantly from that for the healthy controls (116.3) $(F=0.023)$. These estimates based on GIT scores are above average. There were statistically significant differences in age, sex, and education between the groups.

The results of the patient and healthy control groups were free of statistical outliers (all data fell within 2 SD of the group mean), indicating that the overall results are not disproportionately influenced by the test performance of one particular patient or control.

Patients did not show evidence of any difficulty with selective attention functioning (SCWT, card III 
Table 1

Demographic and clinical characteristics

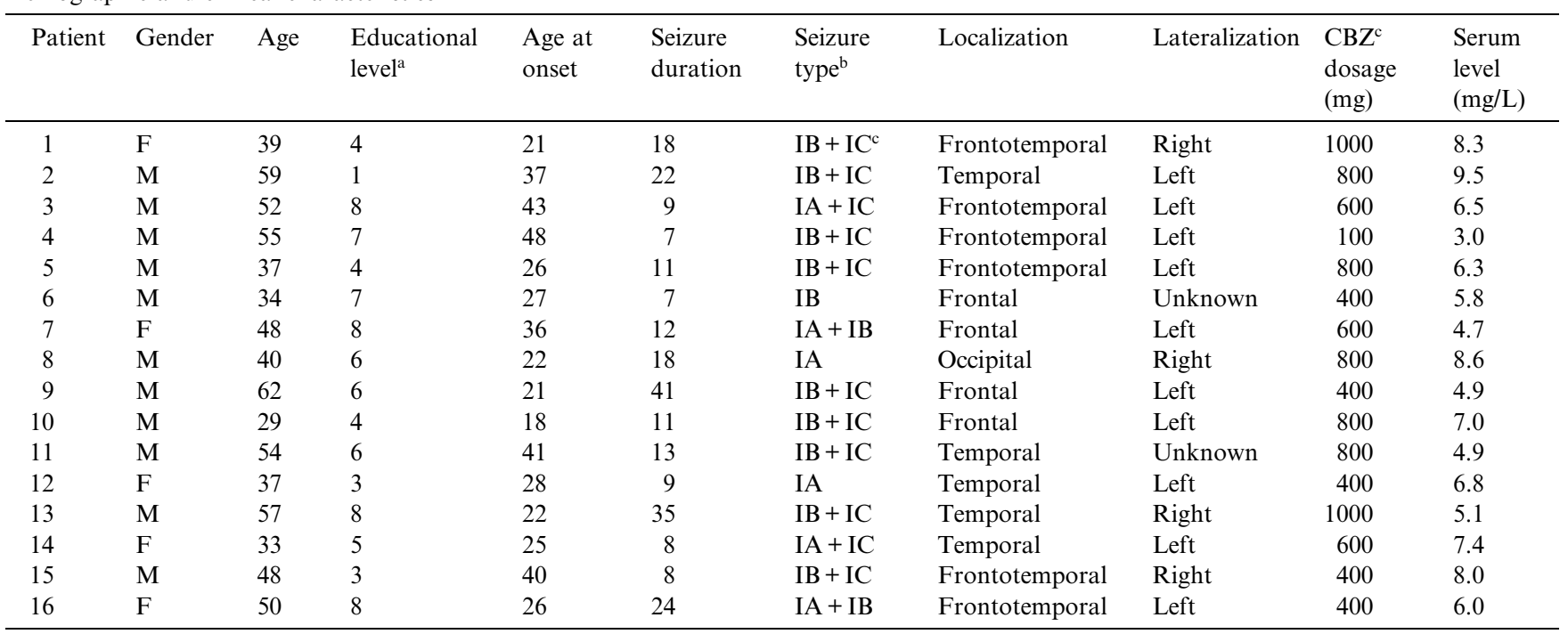

${ }^{\text {a }}$ Educational level was classified according to a Dutch scoring system, ranging from 1 (incomplete primary) to 8 (university).

${ }^{\mathrm{b}}$ IA, simple partial seizures, IB, complex partial seizures, IC, secondarily generalized seizures.

${ }^{\mathrm{c}} \mathrm{CBZ}$, carbamazepine.

$F=1.228$ and Interference $F=5.773$ ). Slower information processing was found when patients had to read words and name colors (SCWT) (card I $F=7.686$,
$P=0.008$, and card II $F=11.590, P=0.003$ ) (Table 2). No problems with memory functioning were found on primary recall of newly presented information or long-

Table 2

Neuropsychological test scores and scores on subscales of the SF-36, measuring health-related quality of life (HRQOL) of patients with well-controlled epilepsy and healthy controls ${ }^{\mathrm{a}}$

\begin{tabular}{|c|c|c|c|}
\hline Variables & Patients with epilepsy $(n=16)$ & Healthy controls $(n=16)$ & $P^{\mathrm{b}}$ \\
\hline \multicolumn{4}{|l|}{ Neuropsychological test scores } \\
\hline \multicolumn{4}{|l|}{ IQ estimate } \\
\hline GIT sum (nc) & $115.8 \pm 0.165$ & $116.3 \pm 12.2$ & NS \\
\hline \multicolumn{4}{|l|}{ Memory (VVLT) } \\
\hline Trial 1 (nc) & $6.4 \pm 1.5$ & $6.1 \pm 1.6$ & NS \\
\hline $\operatorname{Max}(\mathrm{nc})$ & $11.1 \pm 2.4$ & $12.0 \pm 2.0$ & NS \\
\hline Delayed recall (nc) & $9.1 \pm 2.8$ & $9.4 \pm 3.3$ & NS \\
\hline \multicolumn{4}{|l|}{ Attention (SCWT) } \\
\hline Card I (s) & $46.0 \pm 8.6$ & $38.7 \pm 4.6$ & $<0.008$ \\
\hline Card II (s) & $60.3 \pm 10.6$ & $49.9 \pm 6.4$ & $<0.003$ \\
\hline Card III (s) & $90.1 \pm 21.0$ & $83.4 \pm 14.3$ & NS \\
\hline \multicolumn{4}{|l|}{ HRQOL scores $(\mathrm{SF}-36)^{\mathrm{c}}$} \\
\hline Physical compound score (PCS) & $47.8 \pm 8.3$ & $50.0 \pm 9.2$ & NS \\
\hline Mental compound score (MCS) & $46.7 \pm 9.4$ & $52.7 \pm 12.6$ & NS \\
\hline \multicolumn{4}{|c|}{ Self-perceived neuropsychological functioning $(\mathrm{CFQ})^{\mathrm{d}}$} \\
\hline Total score & $46.2 \pm 13.7$ & $30.9 \pm 11.2$ & $<0.002$ \\
\hline
\end{tabular}

${ }^{\mathrm{a}}$ See methods for explanation of abbreviations of variables. nc, Number of correct responses.

${ }^{\mathrm{b}}$ Values of univariate analyses of variance (ANOVAs) between patients with epilepsy and healthy age-, gender-, and education-matched controls.

${ }^{\mathrm{c}}$ Healthy controls for the SF-36 were derived from a different sample than the sample for the neuropsychological tests. Higher scores indicate better HRQOL.

${ }^{\mathrm{d}}$ Higher scores indicate more problems with self-perceived neuropsychological functioning. 
term memory consolidation $(F=0.098$ and $F=0.052$, respectively). Executive functioning was also not impaired $(F=0.333)$.

Self-perceived health-related quality of life is also depicted in Table 2. On average, the SF-36 compound scores showed no significant difference between the patients and the healthy controls (PCS $F=0.545$ and MCS $F=2.433$ ). However, self-perceived neuropsychological functioning (CFQ) (total score) was lower in the patient group than in the healthy controls $(P=0.002, F=12.049)$.

There were no statistically significant correlations between self-perceived neuropsychological functioning (CFQ), on the one hand, and objective neuropsychological functioning in any cognitive domain, self-perceived health-related quality of life (MCS, PCS), and self-perceived mood (POMS), on the other hand.

\section{Discussion}

The aim of this study was to investigate if seizure-free patients have normal objective neuropsychological functioning and HRQOL, although they may report lower levels of self-perceived neuropsychological functioning.

Overall self-perceived health-related quality of life is not suppressed in the present study which is in accordance with previous studies on well-controlled epilepsy $[11,26]$. However, lower levels of self-perceived neuropsychological functioning were reported by the patients in the present study. This is in accordance with our previous study on relatively well-controlled epilepsy patients [14]. The performance of the patients was slower than that of healthy controls. No impairments in selective attention, memory functioning, or executive functioning were found. However, these findings contrast with our previous study [14], in which we found impaired neuropsychological functioning on all cognitive domains mentioned above. It confirms the notion that well-controlled epilepsy patients with an age of onset after 18 years with a long duration of epilepsy and without seizures are a distinct category of patients different, than the more elaborate patient group mentioned above, as demonstrated recently by Shackleton et al. [26]. These patients did experience a maximum of one seizure per month, without restrictions in age at onset and epilepsy duration.

Early detection of slowness is important to be able to offer patients a cognitive rehabilitation program aimed at improving information processing [27] in daily life functioning.

The diminished speed of information processing we found has also been established by pharmacological studies and might be due to the carbamazepine medi- cation $[28,29]$. Although CBZ dosage and serum level were not related to cognition in our previous study on relatively well-controlled epilepsy [14], in this study the serum level was within the standard therapeutic range which makes it unlikely to find a correlation. We therefore cannot exclude that cognitive slowing can be partially due to CBZ.

Self-perceived neuropsychological functioning appeared not to be related to objective neuropsychological functioning, HRQOL, and mood. Other studies could not find a simple association between self-perceived neuropsychological functioning and objective neuropsychological functioning as well [30].

Since no association with cognition was found, we discuss other determinants that might result in low levels of self-perceived neuropsychological functioning. First, differential cognitive behavior is a possible determinant for the problems the patients report about cognitive functioning. Differential cognitive behavior means individual differences in the success with which patients use devices and techniques to improve cognitive processes. Inadequate cognitive behavior may result in cognitive complaints. Only then it is advisable to offer time-consuming cognitive rehabilitation programs since they can provide the patient with new insights [31]. In line with this reasoning, coping strategies as applying avoidance rather than problem-focused coping strategies are found to be related to adjustment problems and could give rise to cognitive complaints. However, this effect was studied only in a mixed patient group including well-controlled epilepsy patients [32].

Second, factors related to chronic illness rather than epilepsy per se can be held responsible for the lower levels of self-perceived neuropsychological functioning. The limitation of activities and aspirations and the various social and economic stresses associated with chronic disorders in general may give rise to negative self-evaluations. As a result some chronically ill subjects may overestimate their cognitive problems [30]. Brown and $\mathrm{McNeill} \mathrm{[33]} \mathrm{also} \mathrm{suggested} \mathrm{that} \mathrm{memory} \mathrm{complaints}$ may represent a combination of general dissatisfaction with psychosocial status as well as self-perceived limitations in abilities. If coping strategies are not adequate and difficulties with accepting a chronic illness are observed, referral to a psychologist for counseling seems more appropriate than cognitive rehabilitation programs.

A limitation of this study is the small sample size of our group, but this is a consequence of the carefully chosen inclusion and exclusion criteria that make our patient group unique in the current literature on objective neuropsychological functioning and HRQOL in epilepsy. A limited number of tests and questionnaires were administered to minimize the possibility of finding significant results due to chance factors. However, we 
selected the test so that all important cognitive areas were covered.

To summarize, the present data support the assumption that well-controlled epilepsy patients with late age at onset and relatively long duration of epilepsy have no overall impaired HRQOL. However, when selfperceived neuropsychological functioning was investigated in detail, difficulties were reported. Lower speed of information processing was also found. Therefore, when patients become seizure-free with adequate medication, cognition still needs to be monitored by the psychologist.

\section{References}

[1] Kemp S, Morley S, Anderson E. Coping with epilepsy: Do illness representations play a role? Br J Clin Psychol 1999;38:43-58.

[2] Reynolds EH. Early treatment and prognosis of epilepsy. Epilepsia 1987;28:97-106.

[3] Collings JA. Epilepsy and well-being. Social Sci Med 1990;31:16570.

[4] Battaglia D, Rando T, Deodato F, et al. Epileptic disorders with onset in the first year of life: neurological and cognitive outcome. Eur J Paediatr Neurol 1999;3:95-103.

[5] Strauss E, Loring D, Chelune G, et al. Predicting cognitive impairment in epilepsy: findings from the Bozeman epilepsy consortium. J Clin Exp Neuropsychol 1995;17:909-17.

[6] Jokeit H, Ebner A. Long term effects of refractory temporal lobe epilepsy on cognitive abilities: a cross sectional study. J Neurol Neurosurg Psychiatry 1999;67:44-50.

[7] Dikmen S, Matthews CG, Harley JP. The effect of early versus late onset or major motor epilepsy upon cognitive-intellectual performance. Epilepsia 1975;16:73-81.

[8] Baker GA, Jacoby A, Buck D, Stalgis C, Monnet D. Quality of life of people with epilepsy: a European study. Epilepsia 1997;38:353-62.

[9] Baker GA, Gagnon D, McNulty P. The relationship between seizure frequency, seizure type and quality of life: findings from three European countries. Epilepsy Res 1998;30:231-40.

[10] Devinsky O, Westbrook L, Cramer J, Glassman M, Perrine K, Camfield C. Risk factors for poor health-related quality of life in adolescents with epilepsy. Epilepsia 1999;40:1715-20.

[11] Jacoby A. Epilepsy and the quality of everyday life: findings from a study of people with well-controlled epilepsy. Social Sci Med 1992;34:657-66.

[12] Leidy NK, Elixhauser A, Vickrey B, Means E, Willian MK. Seizure frequency and the health-related quality of life of adults with epilepsy. Neurology 1999;53(1):162-6.

[13] Loiseau P, Strube E, Broustet D, Battellochi S, Gomeni C, Morselli PL. Learning impairment in epileptic patients. Epilepsia 1983;24:183-92.
[14] Engelberts NHJ, Klein M, Van der Ploeg HM, et al. Cognition and health-related quality of life in a well-defined subgroup of patients with partial epilepsy. J Neurol 2002;249:290-4.

[15] Houx PJ, Jolles J. Age-related decline of psychomotor speed: effects of age, brain health, sex, and education. Percept Motor Skills 1993;76:195-211.

[16] Jolles J, Houx P, Van Boxtel M, Ponds R. Maastricht aging study: determinants of cognitive aging. Maastricht: Neuropsych; 1995.

[17] McHorney C, Ware J, Lu R. The MOS 36-item short form health survey (SF36): III. Tests of data quality, scaling assumptions, and reliability across different patients groups. Med Care 1994;32:4066.

[18] Aaronson NK, Muller M, Cohen PD, et al. Translation, validation, and norming of the Dutch language version of the SF-36 Health Survey in community and chronic disease populations. J Clin Epidemiol 1998;51(11):1055-68.

[19] Luteijn F, Van der Ploeg FAE. Handleiding Groninger Intelligentie Test (Manual Groningen Intelligence Test). Lisse: Swets \& Zeitlinger; 1982.

[20] Stroop JR. Studies of interference in serial verbal reactions. J Exp Psychol 1935:643-62.

[21] Brand N, Jolles J. Learning and retrieval rate of words presented auditorily and visually. J Gen Psychol 1985;112:201-10.

[22] Lezak MD. Neuropsychological assessment. third ed. New York: Oxford University Press; 1995.

[23] Merckelbach H, Muris P, Nijman H, de Jong P. Self-reported cognitive failures and neurotic symptomatology. Pers Individual Diff 1996;20:715-24.

[24] McNair D, Loor M, Droppleman L. Profile of mood states. San Diego, CA: Educational and Industrial Testing Service; 1981.

[25] Nyenhuis DL, Yamamoto C, Luchetta T, Terrien A, Parmentier A. Adult and geriatric normative data and validation of the profile of mood states. J Clin Psychol 1999;55:79-86.

[26] Schackleton DP, Kasteleijn-Nolst Trenite DGA, Vandenbroucke JP, Westendorp RGJ. Living with epilepsy: long term prognosis and psychosocial outcomes. Neurology 2002 [in press].

[27] Fasotti L, Kovacs F, Eling PATM, Brouwer WH. Time pressure managment as a compensatory strategy training after closed head injury. Neuropsychol Rehab 1999.

[28] Meador KJ, Loring DW, Ray PG, et al. Differential cognitive effects of carbamazepine and gabapentin. Epilepsia 1999;40:127985.

[29] Trimble MR. Anticonvulsant drugs and cognitive function: a review of the literature. Epilepsia 1987;28:S37-45.

[30] Vermeulen J, Aldenkamp AP, Alpherts WC. Memory complaints in epilepsy: correlations with cognitive performance and neuroticism. Epilepsy Res 1993;15:157-70.

[31] Engelberts NHJ, Klein M, Ader HJ, Heimans JJ, Kasteleijn-Nolst Trenité DGA, van der Ploeg HM. The effectiveness of cognitive rehabilitation for attention deficits in focal seizures: a randomizedcontrolled study. Epilepsia 2002;43:587-95.

[32] Kemp S, Morley S, Anderson E. Coping with epilepsy: do illness representations play a role?. Br J Clin Psychol 1999;38:43-58.

[33] Brown R, McNeill D. An investigation of the relationship between self-report of memory functioning and memory test performance. J Clin Psychol 1991;47:772-7. 